\title{
Knockdown of p57 gene inhibits breast cancer cell proliferation
}

\author{
TAI PING ZHAO ${ }^{1}$, XIN LIANG WANG ${ }^{2}$ and YI MIN HAN ${ }^{3}$ \\ ${ }^{1}$ College of Health Sciences, Guangzhou Medical University, Guangzhou, Guangdong 510450; \\ ${ }^{2}$ Guangzhou First People's Hospital, Guangzhou, Guangdong 510180; ${ }^{3}$ Department of Oncology, \\ Harbin Medical University Cancer Hospital, Harbin, Heilongjiang 150081, P.R. China
}

Received July 21, 2016; Accepted November 14, 2016

DOI: $10.3892 / \mathrm{ol} .2018 .8605$

\begin{abstract}
The aim of the study was to investigate possible effects of $p 57$ on the grow th of the human MCF-7 and rat SHZ-88 breast cancer cell lines. Specific oligonucleotide sequences containing small hairpin structure were inserted into a small interfering RNA (siRNA) expression vector. The human MCF-7 and rat SHZ-88 breast cancer cell lines were transfected with recombinant plasmids. The $p 57$ gene expression was blocked in the human MCF-7 breast and rat SHZ- 88 breast cancer cells, using chemically modified siRNA. The p57 expression level was evaluated using quantitative polymerase chain reaction (qPCR) and western blot analysis. Immunofluorescence was conducted to detect p57 expression in the breast cancer cells. Tetrazolium blue (MTT) method was employed to detect the effect of p57 inhibition on the proliferation of the MCF-7 and SHZ-88 cell lines. Cell proliferation in the experimental group was significantly reduced. Immunofluorescence assay results showed p57 siRNA effectively inhibited the p57 level in the MCF-7 and SHZ-88 cells. RT-PCR results showed that $48 \mathrm{~h}$ after transfection, the p57 mRNA level in the transfected group was significantly lower compared with the control group. In conclusion, p57 effectively inhibited the proliferation of breast cancer after stable interference.
\end{abstract}

\section{Introduction}

Breast cancer ranks second in female cancer mortality rate, and the incidence rate in developing countries is on the increase (1). Cell cycle-dependent kinase inhibitor p57 is a tumor suppressor gene coding for a multifunctional protein involved in cell proliferation regulation, apoptosis, cell differentiation,

Correspondence to: Dr Tai Ping Zhao, College of Health Sciences, Guangzhou Medical University, 802 Guanghua No. 2 Road, Guangzhou, Guangdong 510450, P.R. China

E-mail: 1140511921@qq.com

Dr Yi Min Han, Department of Oncology, Harbin Medical University Cancer Hospital, 150 Haping Road, Harbin, Heilongjiang 150081, P.R. China

E-mail: 13435687426@163.com

Key words: small interfering RNA, MCF-7 cells, SHZ-88 cells, p57 gene tumor invasion, metastasis and angiogenesis (2-4). Previous findings showed that in a variety of human tumor cells, p57 was downregulated, suggesting that low levels of p57 increased the risk of malignant tumor development. Thus, p57 downregulation is important in the pathogenesis of human ovarian cancer, gastric cancer, colorectal cancer and lymphoma $(5,6)$.

There are reports suggesting that $\mathrm{p} 57$ downregulation is linked to the onset and development of breast cancer (7). In the present study, we investigated the effects of p57 on two breast cancer cell lines. The results however did not show any effects of knocked down p57 gene on breast cancer cell proliferation.

\section{Materials and methods}

Materials. Human HMCF-7 and rat SHZ-88 breast cancer cell lines were purchased from the Shanghai Institute of Cell Research, Chinese Academy of Sciences (Shanghai, China). The cells were cultured in media containing $10 \%$ fetal bovine serum RPMI-1640 (Gibco BRL, Gaithersburg, MD, USA), with $5 \% \mathrm{CO}_{2}$ at $37^{\circ} \mathrm{C}$ in a humid environment.

Main reagent. Lipofectamine ${ }^{\circledR} 2000$ and TRIzol reagent (Invitrogen Life Technologies, Carlsbad, CA, USA); AMV First Strand cDNA Synthesis kit (Toyobo Co., Ltd., Osaka, Japan); and anti-p57 antibody (rb-1527) (Lab Vision/neomarkers, San Diego, CA, USA) were used in the present study.

Small interfering RNA (siRNA) design synthesis. p57 mRNA sequences in human and rat were obtained from NCBI, and siRNAs were designed based on mRNA sequences using siRNA online design software and structure 4.4 (8-10). In order to enhance the stability of siRNA, the sense chain was modified by fluorine (chemical was produced by the Shanghai Jima Company, Shanghai, China).

\section{Experimental method}

Transfection. We used Lipofectamine ${ }^{\circledR} 2000$ for transfection. Transfection conditions were optimized using the negative control siRNA with universal fluorescent labeling. Cells in the logarithmic growth phase were collected and cell density was adjusted. The cells were inoculated into a 12-well plate containing RPMI-1640 culture medium with $10 \%$ serum without antibiotics. Lipofectamine ${ }^{\circledR} 2000$ reagent was diluted in culture medium without serum and antibiotics. At $24 \mathrm{~h}$ later, 
the previous culture medium was discarded and replaced with diluted Lipofectamine ${ }^{\circledR} 2000$ reagent and siRNA. They were mixed for $5 \mathrm{~min}$ and after $20 \mathrm{~min}$ at room temperature they were incubated for $6 \mathrm{~h}$ and then observed under a fluorescent microscope (IX70; Olympus,Tokyo, Japan).

Cell proliferation was detected by CCK- 8 method. Normal and transfected human MCF-7 and rat SHZ-88 breast cancer cells were inoculated into a 96 -well plate $\left(5 \times 10^{3}\right.$ cells/well). Cell proliferation was measured at 1,2, 3 and 4 days after culture. CCK-8 (10 $\mu \mathrm{l})$ reagent was added to each well followed by $2 \mathrm{~h}$ incubation at $37^{\circ} \mathrm{C}$, and absorbance was measured at $450 \mathrm{~nm}$. The absorbance value represented cell proliferation.

Immunofluorescence. MCF-7 and SHZ-88 breast cancer cells were inoculated into 12 -well plates with coverslips $\left(1 \times 10^{5} / \mathrm{ml}\right.$, $1 \mathrm{ml}$ per well). After $48 \mathrm{~h}$ incubation, the cells were washed with PBS twice, and fixed with $4 \%$ formaldehyde at room temperature for $10 \mathrm{~min}$. Then, $0.2 \%$ Triton $\mathrm{X}-100$ was added and left at room temperature for $10 \mathrm{~min}$. BSA (2\%) was added, followed by $30 \mathrm{~min}$ incubation. Anti-p57 antibody (dilution, 1:50) was added and the sample was incubated at $4^{\circ} \mathrm{C}$ overnight. After incubation, the cells were washed three times with PBS, 5 min each time, and secondary anti FITC-IgG (dilution, 1:100) was added at room temperature followed by $1 \mathrm{~h}$ incubation in the dark. The samples were then examined under a fluorescent microscope.

RT-polymerase chain reaction $(P C R)$ detection. Total RNA was extracted and the concentration was measured using a UV spectrophotometer (Hitachi, Ltd., Tokyo, Japan) and the integrity of RNA was examined by electrophoresis (A260/A280 ratio was 1.8-2). cDNA FastQuant was used for cDNA synthesis. The reaction conditions were: $95^{\circ} \mathrm{C}$ for $3 \mathrm{~min}$ and $42^{\circ} \mathrm{C}$ for $15 \mathrm{~min}$, and then kept on ice. Primer sequences are presented in Table I.

Western blot analysis. Lysis solution (including protease inhibitor) was added and the cells were ground (on ice). The sample was centrifuged at $12,000 \mathrm{x}$ g for $20 \mathrm{~min}$ at $4^{\circ} \mathrm{C}$ and supernatant was collected. Protein content in the supernatant was quantified and the sample was electrophoresed (10\% SDS-PAGE) and transferred to a PVDF membrane. The membrane was incubated with skimmed milk $(10 \%)$ for $1 \mathrm{~h}$ and rabbit monoclonal p57 antibody (dilution, 1:1,000; cat. no. ab75974; Abcam, Cambridge, MA, USA) was added and the membrane was incubated at $4^{\circ} \mathrm{C}$ overnight. The membrane was washed with TTBS followed by adding secondary goat anti-rabbit (HRP) IgG antibody (dilution, 1:2,000; cat. no. ab6721; Abcam) and incubating at room temperature for $1 \mathrm{~h}$. The membrane was washed with TTBS and color-substrate solution was added.

Statistical analysis. SPSS 17.0 software (IBM SPSS, Armonk, NY, USA) was used for statistical analysis. The Kaplan-Meier method was used for single factor analysis of the relevant data in survival analysis. Log-rank test was employed for comparisons of significant difference. The Cox proportional hazard model was used to study the effects of various clinical and pathological factors on the recurrence time. $\mathrm{P}<0.05$ was considered to indicate a statistically significant difference.
Table I. RT-polymerase chain reaction primer sequences of p57 mRNA of MCF-7 and SHZ-88 cells.

\begin{tabular}{ll} 
Gene name & \multicolumn{1}{c}{ Primer sequence } \\
\hline MCF-7 & 5'-3' CTGATCTCCGATTTCTTCGC \\
& 3'-5' TCTTTGGGCTCTAAATTGG \\
SHZ-88 & 5'-3' TCTCCTGTCCTGTGTGCCTACC \\
& 3'-5' CAGGTCAACTGCCTACACAGAGC
\end{tabular}
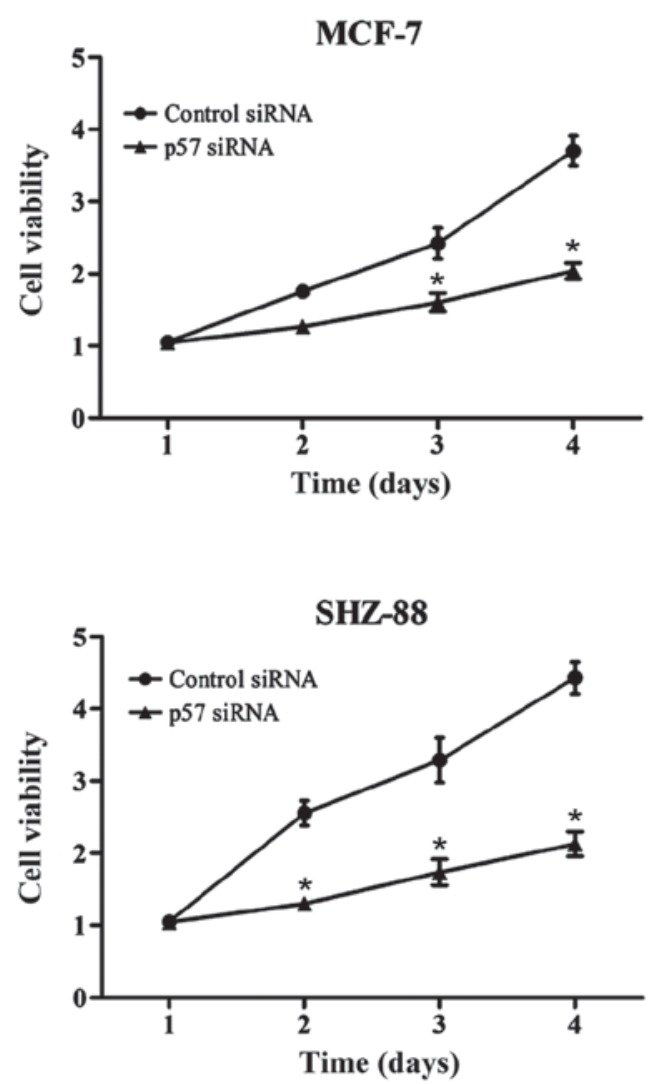

Figure 1. CCK-8 method to detect the proliferation activity of MCF-7 and SHZ- 88 breast cancer cells after transfection of small interfering RNA (siRNA) compared with the blank control group. "P<0.05.

\section{Results}

Cell proliferation after p57 interference. Cell proliferation in the experimental group was significantly reduced. In the MCF-7 cells, absorbance value in the experimental group and the negative control group were $2.67 \pm 0.09$ and $3.87 \pm 0.12$, respectively. In the SHZ-88 cells these values were $2.06 \pm 0.07$ and $4.37 \pm 0.12$ in the experimental and negative control groups, respectively. Differences were statistically significant $(\mathrm{P}<0.05$; Fig. 1).

Immunofluorescent assay. siRNA effectively inhibited the p57 expression in MCF-7 and SHZ-88 cells. Compared with the control group, p57 protein levels were significantly lower in the siRNA-transfected cells. Immunofluorescent assay showed that p57 was expressed in the MCF-7 and SHZ-88 cells, $48 \mathrm{~h}$ after transfection (Fig. 2). 


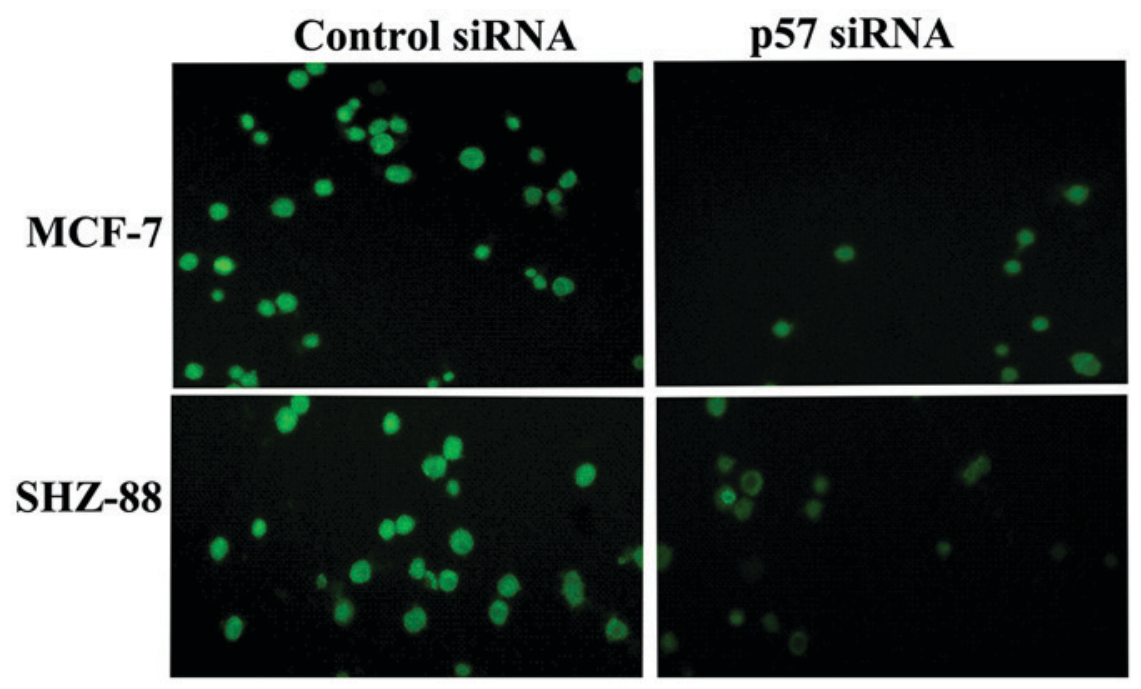

Figure 2. p57 expression in the MCF-7 and SHZ-88 cells ( $\mathrm{P}<0.01)$. siRNA, small interfering RNA.

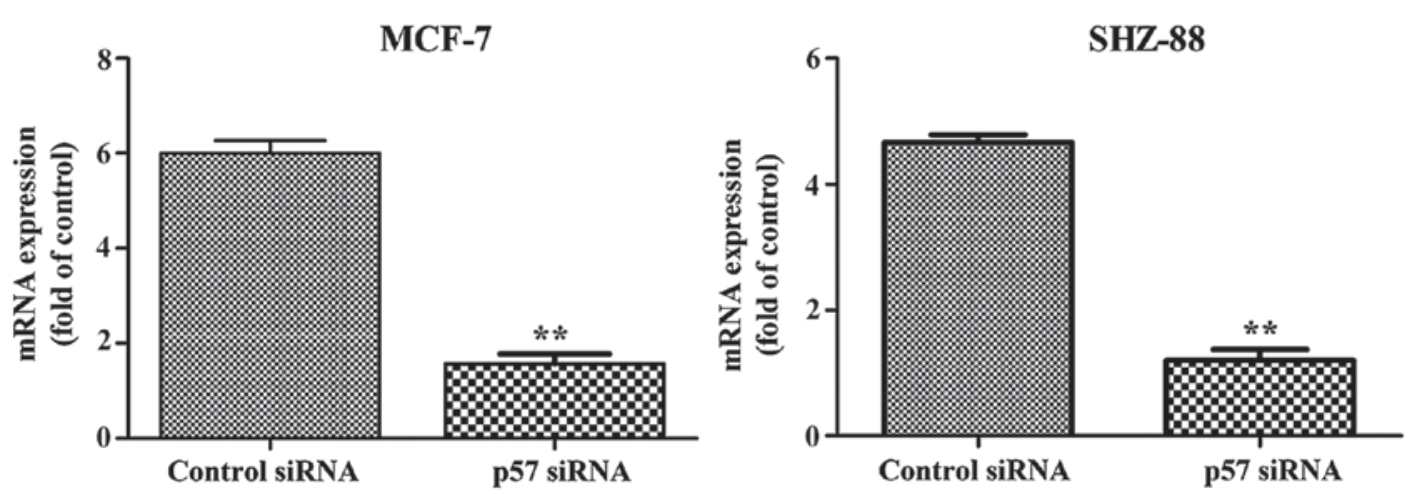

Figure 3. p57 expression in MCF-7 and SHZ-88 cells ( $\left.{ }^{* *} \mathrm{P}<0.01\right)$. siRNA, small interfering RNA.

A
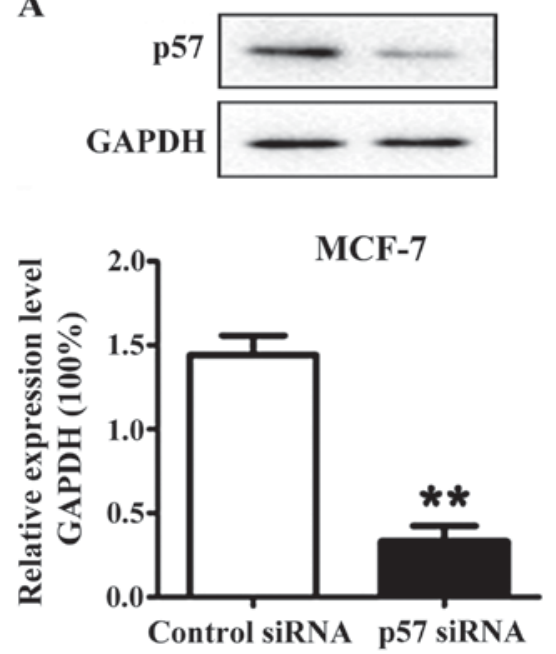

B

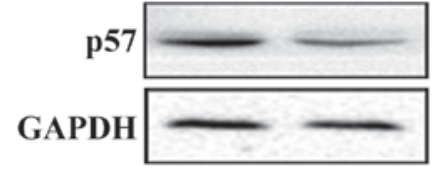

SHZ-88

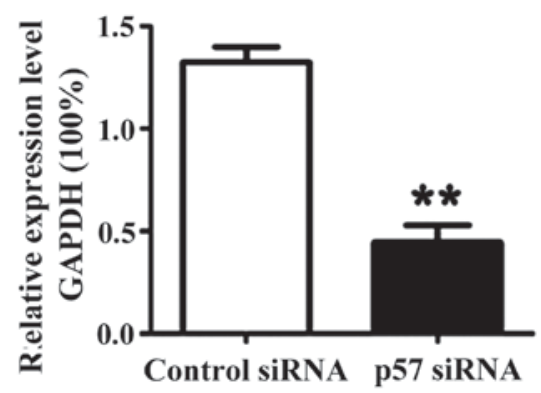

Figure 4. p57 protein expression in the (A) MCF-7 and (B) SHZ-88 cells ( $\left.{ }^{* *} \mathrm{P}<0.01\right)$. siRNA, small interfering RNA.

Effect of p57 siRNA on p57 transcription and translation. RT-PCR results showed that $48 \mathrm{~h}$ after transfection, the mRNA level in the transfected group was significantly lower compared with the control group (Fig. 3). This suggested that the design of our siRNA was successful and siRNA was able to effectively inhibit the $p 57$ gene transcription in the MCF-7 and SHZ-88 cells. The results obtained from western blotting showed that the level of p57 protein was significantly lower in the transfected cells, which suggested that the design of our siRNA was successful (Fig. 4). 


\section{Discussion}

Breast cancer is one of the most common malignant tumors in women. In China, the incidence of this type of cancer ranks first. According to GLOBOCAN 2008 statistics, new cases of breast cancer accounted for $23 \%$ of all tumors in 2011 , and accounted for $14 \%$ of all cancer deaths (11-14). Tumor formation is associated with the out-of-control cell cycle regulation (15). The cell cycle control mechanism includes cyclins, cyclin-dependent protein kinases (CDKs) and cyclin-dependent kinase inhibitor (CKI). Any disturbance in the mechanisms that control these factors can potentially lead to excessive cell proliferation, reduction of apoptosis and tumor formation. p57 is a CKI that belongs to the Cip/Kip family, which includes p21, p27 and p57. p57 can regulate cell cycle progression and is involved in the regulation of transcription, apoptosis, differentiation, development, and migration. p57 is a tumor suppressor that can regulate cyclins, CDKs and cyclin-CDK complexes in the G1-S transition, modulating DNA replication (16). Therefore, absence of p57 may result in an unusual increase in the number of cells in $S$ phase (16). It has been reported that P57 protein is downregulated in colon cancer (17), gastric cancer (18) and human brain glioma (19,20).

In the present study, we blocked the expression of p57 in human and rat breast cancer cell lines (MCF-7 and SHZ-88) by transfecting cells using Lipofectamine ${ }^{\circledR} 2000$ and specific p57 siRNAs. The results showed that p57 siRNA successfully knocked down the expression of p57. We demonstrated that the construction of an appropriate p57 siRNA was directly linked to $\mathrm{p} 57$ silencing efficiency. Thus, the knockdown of p57 cells may be useful in the field of tumor therapy.

\section{Competing interests}

The authors declare that they have no competing interests.

\section{References}

1. Bodai BI and Tuso P: Breast cancer survivorship: A comprehensive review of long-term medical issues and lifestyle recommendations. Perm J 19: 48-79, 2015.

2. Furutachi S, Matsumoto A, Nakayama KI and Gotoh Y: p57 controls adult neural stem cell quiescence and modulates the pace of lifelong neurogenesis. EMBO J 32: 970-981, 2013.

3. Guo H, Li Y, Tian T, Han L, Ruan Z, Liang X, Wang W and Nan K: The role of cytoplasmic p57 in invasion of hepatocellular carcinoma. BMC Gastroenterol 15: 104, 2015.

4. Matsumoto M, Furihata M, Ohtsuki Y, Sasaguri S and Ogoshi S: Immunohistochemical characterization of p57KIP2 expression in human esophageal squamous cell carcinoma. Anticancer Res 20: 1947-1952, 2000.
5. Ma YL, Peng JY, Zhang P, Liu WJ, Huang L and Qin HL: Immunohistochemical analysis revealed CD34 and Ki67 protein expression as significant prognostic factors in colorectal cancer. Med Oncol 27: 304-309, 2010.

6. Ma Y and Cress WD: Transcriptional upregulation of p57 (Kip2) by the cyclin-dependent kinase inhibitor BMS-387032 is E2F dependent and serves as a negative feedback loop limiting cytotoxicity. Oncogene 26: 3532-3540, 2007.

7. Zhao Y, Wang Y, Yang Y, Liu J, Song Y, Cao Y, Chen X, Yang W, Wang F, Gao J, et al: MicroRNA-222 controls human pancreatic cancer cell line capan-2 proliferation by P57 targeting. J Cancer 6: 1230-1235, 2015.

8. Banan M and Puri N: The ins and outs of RNAi in mammalian cells. Curr Pharm Biotechnol 5: 441-450, 2004.

9. Yu JY, DeRuiter SL and Turner DL: RNA interference by expression of short-interfering RNAs and hairpin RNAs in mammalian cells. Proc Natl Acad Sci USA 99: 6047-6052, 2002.

10. Miyagishi M and Taira K: U6 promoter-driven siRNAs with four uridine 3 ' overhangs efficiently suppress targeted gene expression in mammalian cells. Nat Biotechnol 20: 497-500, 2002.

11. Jemal A, Bray F, Center MM, Ferlay J, Ward E and Forman D: Global cancer statistics. CA Cancer J Clin 61: 69-90, 2011.

12. Palmer TD, Ashby WJ, Lewis JD and Zijlstra A: Targeting tumor cell motility to prevent metastasis. Adv Drug Deliv Rev 63: 568-581, 2011.

13. Valastyan S and Weinberg RA: Tumor metastasis: molecular insights and evolving paradigms. Cell 147: 275-292, 2011

14. Holen I, Whitworth J, Nutter F, Evans A, Brown HK, Lefley DV, Barbaric I, Jones M and Ottewell PD: Loss of plakoglobin promotes decreased cell-cell contact, increased invasion, and breast cancer cell dissemination in vivo. Breast Cancer Res 14: R86, 2012.

15. Liu H, Li G, Finch JW, Geromanos SJ and Gebler JC: P57-T Development of an automated RP/RP 2D nanoLC/MS method for proteomic analysis. J Biomol Tech 18: 20, 2007.

16. Bek S, Kreppel D, Bscheider M, Lin CC, Haas T and Poeck H: Activation of RIG-I induces immunogenic cell death. J Immunother Cancer 2: P31, 2014.

17. Tsabouri S, Valari M, Douros K, Gemou-Engesaeth V, Magiakou MA, Papadavid E, Theodoridou M and Priftis K: Prognostic factors for asthma at school age in infants with atopic dermatitis. Clin Transl Allergy 4: P112, 2014.

18. Ullah Z, Kohn MJ, Yagi R, Vassilev LT and DePamphilis ML: Differentiation of trophoblast stem cells into giant cells is triggered by p57/Kip2 inhibition of CDK1 activity. Genes Dev 22: 3024-3036, 2008.

19. Chen Z, Li DQ, Tong L, Stewart P, Chu C and Pflugfelder SC: Targeted inhibition of p57 and p15 blocks transforming growth factor $\beta$-inhibited proliferation of primary cultured human limbal epithelial cells. Mol Vis 12: 983-994, 2006.

20. Joaquin M, Gubern A, González-Nuñez D, Josué Ruiz E, Ferreiro I, de Nadal E, Nebreda AR and Posas F: The p57 CDKi integrates stress signals into cell-cycle progression to promote cell survival upon stress. EMBO J 31: 2952-2964, 2012.

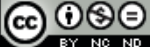

This work is licensed under a Creative Commons Attribution-NonCommercial-NoDerivatives 4.0 International (CC BY-NC-ND 4.0) License. 